\title{
Modelling of large-scale dense gas-solid bubbling fluidised beds using a novel discrete bubble model
}

\author{
G.A. Bokkers, J.A. Laverman, M. van Sint Annaland*, J.A.M. Kuipers \\ Faculty of Science and Technology, University of Twente, P.O. Box 217, 7500 AE Enschede, The Netherlands \\ Received 30 September 2005; received in revised form 31 March 2006; accepted 3 April 2006
}

\begin{abstract}
In order to model the complex hydrodynamic phenomena prevailing in industrial scale gas-solid bubbling fluidised bed reactors and especially the macro-scale emulsion phase circulation patterns induced by bubble-bubble interactions and bubble coalescence, a discrete bubble model (DBM) has been developed. In the DBM, the (larger) bubbles are modelled as discrete elements and are tracked individually during their rise through the emulsion phase, which is considered as a continuum. The DBM, originally developed for the description of gas-liquid flows, has been adapted to cope with bubbles with a diameter larger than the size of an Eulerian cell, which is required in view of the large bubble size distribution at higher gas flow rates. Moreover, a new drag model for a single bubble rising in a fluidised bed derived from empirical correlations has been implemented, as well as a simple model to account for bubble coalescence and break-up. The strong advantage of the DBM compared to other models previously reported in the literature for the description of large-scale fluidised beds is that it fully accounts for the two-way coupling between the bubbles and the emulsion phase, which enables direct computation of the emulsion phase velocity profiles. Comparison of the results of simulations ignoring bubble coalescence and simulations taking bubble coalescence properly into account demonstrated the significant effect of bubble coalescence on the large-scale circulation patterns prevailing in bubbling fluidised beds. The simulation results for the lateral profiles of the visible bubble flow rate have been compared qualitatively with experimental results reported by Werther [1974. Influence of the bed diameter on the hydrodynamics of gas fluidized beds. A.I.Ch.E. Symposium Series 70(141), 53-62]. The effect of the superficial gas velocity on the velocity and porosity profiles has been studied. In general, it can be concluded that the DBM is able to capture the salient features of the hydrodynamics of bubbling fluidised beds. However, further research is required to improve the closure equations for the bubble behaviour, bubble-bubble interactions and bubble coalescence and break-up to enable a complete quantitative description.
\end{abstract}

(C) 2006 Elsevier Ltd. All rights reserved.

Keywords: Discrete bubble model; Fluidisation; Hydrodynamics; Multiphase flow; Bubble coalescence; Computational fluid dynamics; Euler-Lagrange model

\section{Introduction}

Gas phase polymerisation processes are widely employed nowadays for the polymerisation of ethylene (HDPE and LLDPE) and propylene (Choi and Ray, 1985). In this process highly active and highly selective catalysts are used, which results in an enormous heat production in the reactor. In order to remove the liberated reaction energy to avoid sticking of the produced polymer particles, this process employs a fluidised bed reactor, which is known for its excellent heat transfer characteristics. Because the production capacity of this process is limited by the rate of heat removal, this is a major point of

\footnotetext{
* Corresponding author.

E-mail address: M.vanSintAnnaland@utwente.nl (M. van Sint Annaland).
}

attention in the operation and optimisation of this type of reactors. In today's olefin polymerisation processes there exist two main ways to remove the heat of reaction. One operation mode is the injection of liquid monomer in the bottom of the reactor (condensed mode). Due to the fast evaporation of the liquid monomer part of the produced reaction heat is consumed. The second way of removing the reaction energy is via convection of the emulsion phase in the fluidised bed. It is known that large circulation patterns prevail in industrial scale fluidised bed reactors and the higher the circulation rate, the more heat can be removed from the bottom part of the reactor and the higher the production capacity.

To study these large-scale convection patterns detailed hydrodynamic models are required. Earlier work on large-scale fluidised bed modelling has been performed by Krishna and 
van Baten (2001), who modelled large-scale air-FCC fluid beds with diameters ranging from 0.1 to $6.0 \mathrm{~m}$ in diameter. They developed an Euler-Euler two-fluid model, where the emulsion phase was considered as a pseudo liquid and the drag between the bubbles and the dense phase was calculated via the developed Davies-Taylor-Collins relations. In order to account for the influence of the bed diameter and the effect of neighbouring bubbles on the rise velocity of the bubbles, a scale factor and an acceleration factor were implemented in the drag correlation. Moreover, bubble coalescence and break-up was only implicitly accounted for in their model by using an effective average bubble diameter as a function of the superficial gas velocity and the height in the bed, obtained from experimental data.

Another approach to study the global dynamics in gasfluidised beds was presented by Pannala et al. (2003, 2004), who employed an agent-based bubble model, which allows a direct implementation of bubble coalescence. In their model the bubble trajectory of each individual bubble was computed by integrating the bubble velocity in time, where the bubble velocity was made dependent on the distance to its closest leading neighbour, while taking bubble coalescence into account when two bubbles collide. Although, this model has only been used to model fluidised beds with heights smaller than $80 \mathrm{~cm}$, this model should in principle be able to handle large-scale fluidised beds. However, in the presented model the dynamics of the emulsion phase were completely ignored, so that their model is incapable of accounting for and computing the important large-scale circulation patterns in the emulsion phase. The bubbles rising in a fluidised bed will affect the dynamics of the emulsion phase and, vice versa, the emulsion phase velocity patterns will be dominated by the drag exerted by the bubbles (two-way coupling).

A discrete bubble model (DBM) has been developed to study the hydrodynamics in large-scale fluidised beds that fully accounts for the two-way coupling. The emulsion phase is modelled as a continuum and the bubbles are regarded as discrete elements. The bubble trajectories are computed by integrating the equations of motion (Newton's second law), accounting for bubble coalescence when two bubbles collide, using closures for the forces acting on the individual bubbles. More detailed and fundamental models could be used in addition to experiments to derive the required closures for the bubble behaviour and the emulsion phase rheology. With continuum models (Euler-Euler) using closures from the kinetic theory of granular flow for the solids phase rheology, or discrete particle models (Euler-Lagrange), where all the individual particles in the fluidised bed are tracked, the bubbles can in principle be completely resolved and the bubble behaviour could be computed. However, for the simulation of the macro-scale circulation patterns prevailing in large, industrial scale fluidised beds with these fundamental models, the required number of grid cells or the required number of particles and hence the corresponding calculation times would definitely become prohibitive. Therefore, models that are developed to describe the hydrodynamics of very large systems will have to rely on closures for the bubble behaviour. Although, the DBM idealises the bubbles as perfect spheres, its strong advantage is that no a priori assumption is required on the bubble encounter frequency, an important factor determining the bubble coalescence rate.

The DBM, which has been widely used in the field of gas-liquid bubble columns (Lapin and Lübbert, 1994; Sokolichin et al., 1997; Delnoij et al., 1997, 1999), has been somewhat modified to model the hydrodynamics of fluidised beds. Firstly, the DBM together with the closure relations describing the behaviour of bubbles in fluidised beds, including bubble coalescence and splitting, is described. Subsequently, its numerical implementation is shortly presented. After the model verification, simulation results are discussed, focussing on the effect of bubble coalescence and the influence of the gas velocity on the macro-scale flow structures prevailing in large-scale olefin polymerisation reactors.

\section{Discrete bubble model}

\subsection{Model assumptions}

The DBM is an Euler-Lagrange type of model, where the dynamics of the continuous emulsion phase is modelled with the continuity and volume-averaged Navier-Stokes equations and solved on an Eulerian grid, while the bubbles are tracked individually by integrating the equations of motion. A detailed collision model accounts for the bubble-bubble and bubblewall interactions, including coalescence between bubbles. Constitutive relations are required for the drag force exerted on the bubbles, which are derived from empirical correlations for the terminal rise velocity of a single bubble in fluidised beds, and for the virtual mass force. The emulsion phase density and viscosity are assumed constant (and known from experiments).

\subsection{Emulsion phase hydrodynamics}

The emulsion phase, representing a mixture of particles and gas, is described with the continuity equation and the incompressible volume-averaged Navier-Stokes equations

$$
\begin{aligned}
& \frac{\partial\left(\varepsilon_{e} \rho_{e}\right)}{\partial t}+\nabla \cdot \varepsilon_{e} \rho_{e} \bar{u}=0, \\
& \frac{\partial\left(\varepsilon_{e} \rho_{e} \bar{u}\right)}{\partial t}+\nabla \cdot \varepsilon_{e} \rho_{e} \bar{u} \bar{u}=-\varepsilon_{e} \nabla P-\nabla \cdot \varepsilon_{e} \overline{\bar{\tau}}_{e}+\varepsilon_{e} \rho_{e} \bar{g}+\bar{S},
\end{aligned}
$$

where $\bar{S}$ is the source term that accounts for the momentum transfer between the bubbles and the emulsion phase. For the viscous stress tensor, the closure for a Newtonian fluid has been adopted, although the dense fluidised suspensions exhibit features of Bingham fluids (see van den Langenberg-Schenk, 1982).

\subsection{Bubble dynamics}

The bubbles in the DBM are considered as discrete spherical elements which are tracked individually according to Newton's second law of motion:

$m_{b} \frac{\mathrm{d} \bar{v}_{b}}{\mathrm{~d} t}=\sum \bar{F}=\bar{F}_{g}+\bar{F}_{p}+\bar{F}_{d}+\bar{F}_{v m}$, 
where $\bar{F}_{g}$ is the gravity force, $\bar{F}_{p}$ the pressure force, $\bar{F}_{d}$ is the drag force which is the flow resistance of the moving bubble with the emulsion and $\bar{F}_{v m}$ is the virtual mass force which accounts for the acceleration of the emulsion phase directly surrounding the bubble if a bubble is accelerated. Here, the force resulting from bubble-bubble interactions (wake acceleration force) has been ignored. Its effect will be studied in future work. Furthermore, it has been assumed that the bubbles have no net gas exchange with the emulsion phase so that the bubbles only grow due to coalescence. Mass transfer between the bubbles and the emulsion phase could in principle be included in the DBM (see Darmana et al., 2005a), but has not been implemented yet. Moreover, in case chemical reactions take place in the bulk of the emulsion phase the DBM should be extended to describe the gas flow through the emulsion phase, e.g. via a multifluid continuum description of the emulsion phase.

The sum of the pressure and the gravity force, is given by

$\bar{F}_{g}+\bar{F}_{p}=\left(\rho_{e}-\rho_{g}\right) V_{b} \bar{g}$.

The drag force on a sphere is computed with the equation by Odar and Hamilton (1964):

$\bar{F}_{d}=-\frac{1}{2} C_{D} \rho_{e} \pi R_{b}^{2}|\bar{u}-\bar{v}|(\bar{u}-\bar{v})$,

where $R_{b}$ is the radius of the bubble, $C_{D}$ is the drag coefficient and $\bar{u}$ and $\bar{v}$ are the emulsion and bubble velocity, respectively. A correlation for the drag coefficient will be proposed in Section 2.6.

The last force incorporated in the force balance is the virtual mass force, for which the relation derived by Auton (1983) is used

$\bar{F}_{v m}=-\left(\frac{D \bar{I}}{D t}+\bar{I} \cdot \nabla \bar{u}\right)$,

$\bar{I}=C_{v m} \rho_{l} V_{b}(\bar{v}-\bar{u})$,

where $C_{v m}$ is assumed to be equal to 0.5 .

\subsection{Visible bubble flow rate}

In the DBM the initial bubble formation and bubble growth close to the distribution plate is not modelled. Instead, bubbles with a specified initial bubble diameter are injected via nozzles into the emulsion phase, where the number of bubbles that enter the fluidised bed per unit time in the DBM corresponds with the visible bubble flow rate in the fluidised bed. According to the two-phase theory all the gas in excess to that required for minimum fluidisation is assumed to flow through the bed as bubbles. However, it was found experimentally that only part of the excess gas flows through the bed as visible bubbles. Werther (1992) has measured the fraction of the excess gas visible as bubbles for different particles belonging to different classes according to the Geldart classification (Geldart, 1973; Kunii and Levenspiel, 1991). Using this experimental information (see Table 1) and specifying an initial bubble diameter the number of bubbles that enter the bed per unit time can be computed.
Table 1

Parameters for the correlation for the bubble rise velocity by Werther (1992) (Eq. (10))

\begin{tabular}{llll}
\hline & $\mathrm{A}$ & $\mathrm{B}$ & $\mathrm{D}$ \\
\hline$\psi$ & 0.80 & 0.65 & 0.26 \\
$\alpha\left(D_{T}<1\right) m$ & $3.2 D_{T}^{1 / 3}$ & $2.0 D_{T}^{1 / 2}$ & 0.87 \\
$\alpha\left(D_{T}>1\right) m$ & 3.2 & 2.0 & 0.87 \\
\hline
\end{tabular}

A correlation for the initial bubble diameter for a bubble released from a multihole distributor was given by Chiba and Kobayashi (1972)

$d_{b 0}=1.71 g^{-0.2} P_{t}^{0.8}\left(u-u_{m f}\right)^{0.4}$,

where $P_{t}$ is the orifice pitch.

\subsection{Bubble coalescence/break-up}

Besides the motion of the bubbles calculated with the force balance as described before, the bubbles can meet each other and the system walls. A detailed collision model, originally implemented in the discrete particle model by Hoomans (1999), is employed in the DBM which computes every collision one by one (the so-called hard-sphere approach). To avoid that all the bubbles in the bed have to be scanned as a possible collision partner, the model uses small neighbourlists of possible collision partners. From all the neighbourlists the smallest time to a collision is determined, whereafter this collision is carried out. Of course, bubbles in fluidised beds do not bounce, but will coalesce till a maximum size where the largest bubbles start to break-up, at least for Geldart A/B type particles as encountered in polymerisation reactors. In the DBM this process is simplified in such a way that all the bubbles that meet each other will coalesce until a pre-defined maximum bubble size is reached, whereafter these large bubbles will only collide with other bubbles, approximating a dynamic equilibrium between bubble coalescence and break-up. When the new bubble has accidentally overlap with a third bubble, it has been assumed that this bubble also coalesces with the new bubble. This might result in the formation of a bubble diameter slightly larger than the pre-defined 'maximum' bubble diameter. In the DBM, coalescence is carried out with conservation of mass and momentum. The mass of the new bubble equals the sum of the masses of the two colliding bubbles, the new velocity of the bubble is computed from the total momentum balance and the position of the new bubble is the mass averaged position of the bubbles prior to the collision. A more detailed coalescence model could in principle be easily implemented in the DBM, provided that reliable correlations for bubble coalescence and break-up are available.

\subsection{Constitutive equation for the drag coefficient}

To close the governing equations, the DBM requires a constitutive equation for the drag coefficient of the bubbles, which 
is derived from an empirical correlation for the steady rise velocity of a single bubble in a fluidised bed.

\subsubsection{Bubble rise velocity}

Many experimental relations have been derived for the rise velocity of bubbles in a fluidised bed. Main factors influencing the bubble rise velocity are the average diameter of the bubble swarm $\left(d_{b}\right)$, the bed diameter $\left(D_{T}\right)$ and the height of the fluid bed (Krishna and van Baten, 2001). For a single, isolated, bubble with a diameter of $d_{b}$ the rise velocity $v_{b}^{0}$ in a quiescent bed of powder is given by the correlation of Davies and Taylor (1950):

$v_{b}^{0}=0.711 \sqrt{g d_{b}}$.

In a freely bubbling fluidised bed many bubbles rise together in a swarm and the presence of many neighbouring bubbles affects their rise velocity. Moreover, wall effects may become important in small beds $\left(D_{T}<1\right)$. Werther (1992) formulated a general correlation for the bubble rise velocity in A, B and $\mathrm{D}$ powders, where the effect of the bed diameter and swarm effects are incorporated:

$v_{b}=\psi\left(u-u_{m f}\right)+\alpha v_{b}^{0}$,

where $\psi$ is a scale factor accounting for the fraction of visible bubbles and $\alpha$ is a power-law function that incorporates the effect of the bed diameter. The different values measured for $\psi$ and $\alpha$ have been listed in Table 1 . More recently, Krishna and van Baten (2001) adapted the Davies-Taylor relation for Geldart A powders by adding two multiplication factors. Firstly, they added a size factor (SF) accounting for the influence of the bed diameter on the rise velocity of a single bubble, which was measured by Collins (1967) for gas-liquid systems:

$$
\mathrm{SF}= \begin{cases}1, & \frac{d_{b}}{D_{T}}<0.125, \\ 1.13 \mathrm{e}^{-\left(d_{b} / D_{T}\right)}, & 0.125<\frac{d_{b}}{D_{T}}<0.6, \\ 0.496 \sqrt{\frac{D_{T}}{d_{b}}}, & \frac{d_{b}}{D_{T}}>0.6 .\end{cases}
$$

The second factor they added is the wake acceleration factor (AF), since a bubble gets accelerated when it comes into the path of a preceding bubble. The acceleration factor and the averaged bubble diameter were fitted from experimental data, which yielded:

$\mathrm{AF}=1.64+2.7722\left(u-u_{m f}\right)$,

$d_{b}=0.204\left(u-u_{m f}\right)^{0.412}$.

In these modified correlations by Werther (1992) and Krishna and van Baten (2001) the effect of the emulsion phase velocity patterns is indirectly lumped. In our work the two-way coupling is explicitly accounted for via the momentum transfer rate $S$. Hence, a drag correlation is derived from the Davies-Taylor correlation for the rise velocity of a single bubble, where the wake acceleration force has been ignored as a first approximation.

\subsubsection{Drag coefficient}

The drag coefficient for a single bubble rising in a quiescent fluid can easily be computed from the steady state force balance and the Davies-Taylor relation (Eq. 9), yielding:

$m_{b} \frac{\mathrm{d} \bar{v}}{\mathrm{~d} t}=0=\bar{F}_{p}+\bar{F}_{g}+\bar{F}_{d}$,

$\left(\rho_{e}-\rho_{g}\right) \frac{1}{6} \pi d_{b}^{3} \bar{g}=\frac{1}{2} C_{D} \frac{1}{4} \pi d_{b}^{2} \rho_{e} \cdot(0.711)^{2} \bar{g} d_{b}$.

This simplifies to the following constant value for the drag coefficient $C_{D}$ in the usual case that the emulsion phase density largely exceeds the gas density

$C_{D}=\frac{4\left(\rho_{e}-\rho_{g}\right)}{3 \rho_{e}(0.711)^{2}}=2.64 \approx \frac{8}{3}$.

This value resembles the drag coefficient given by Darton and Harrison (1974) for high $\operatorname{Re}_{b}$ (i.e., $\operatorname{Re}_{b}>1000$ ), who derived the following relation for spherical cap bubbles in fluidised beds:

$C_{D}=\frac{16}{R e_{b}}+\frac{8}{3}$

\subsection{Boundary conditions}

To distinguish internal flow cells from the boundaries, a flag matrix (Kuipers et al., 1993) is used as is schematically depicted in Fig. 1. The internal cells indicated with number 1 are completely filled with the continuous emulsion phase. That means that no free surface is modelled here, but the emulsion phase can expand through the free in/outflow cells indicated with number 5 when bubbles enter the computational domain. The other cell flags are explained in Table 2. The bubbles enter the fluidised bed via nozzles that are equally distributed over the entire area of the bottom plate, as can be seen in Fig. 2, to mimic a multihole distributor. Each bubble can be displaced randomly in the $x$ and $y$ direction around a nozzle as is depicted

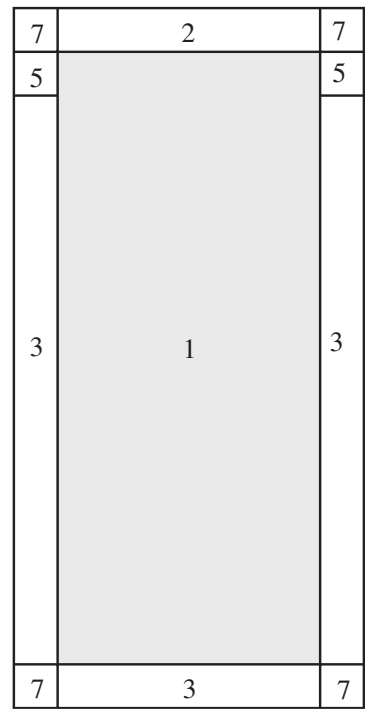

Fig. 1. Flag matrix used in the flow solver. 
Table 2

Cell flags and their corresponding boundary conditions

\begin{tabular}{ll}
\hline Flag & Boundary conditions \\
\hline 1 & Interior cell, no boundary condition \\
2 & Impermeable wall, free slip boundary \\
3 & Impermeable wall, no slip boundary \\
5 & Prescribed pressure cell, free slip boundary \\
7 & Corner cell, no boundary condition \\
\hline
\end{tabular}
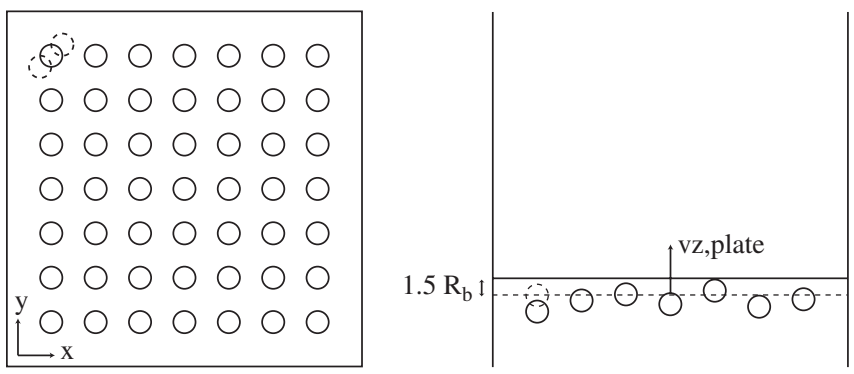

Fig. 2. Bubble inlet procedure; left: configuration of the nozzles and random variation of the $x$ and $y$ positions of the nozzles; right: initial vertical bubble positions.

in the upperleft corner of Fig. 2 by the dashed nozzles. Initially, the vertical $z$-coordinate of the bubbles is randomly determined to avoid that the bubbles enter the bed simultaneously generating an unwanted pressure wave in the fluidised bed. Thereafter, the bubbles rise at the plate with a constant velocity indicated as $v_{z, \text { plate }}$, corresponding with the specified visible bubble flow rate. As soon as the bubble has been released from the plate the movement of the bubble is computed by the force balance as was described before. Bubbles that meet the system walls will bounce fully elastically (no energy dissipation), except collisions with the top of the bed; those bubbles will be removed from the bed.

\subsection{Solution method}

The emulsion phase, described by the incompressible Navier-Stokes equations, are discretised on a staggered grid and the SIMPLE algorithm (Patankar, 1980) is employed to obtain the pressure and velocity fields. The incomplete Cholesky conjugate gradient (ICCG) method is used to solve the pressure Poisson equation. The convective terms in the continuity and momentum equations are computed with the second order accurate Barton scheme (Centrella and Wilson, 1984; Goldschmidt, 2001), while the diffusive terms are calculated with standard second order central discretisations.

The force balances for each bubble are integrated with first order explicit time integration, which is sufficient in view of the small time steps used here to move the bubbles. For further details, the interested reader is referred to Delnoij et al. (1997, 1999), van den Hengel (2004) and Darmana et al. (2005a). The issue that needs to be addressed here is the mapping of Lagrangian properties to the Eulerian grid and vice versa,
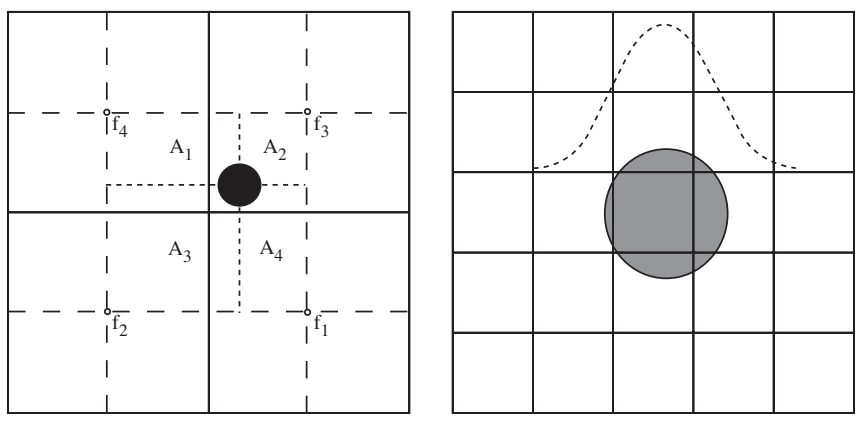

Fig. 3. Mapping of Lagrangian quantities to the Eulerian grid and vice versa. Left: volume-averaging of bubble properties to the surrounding grid points as applied in the original DBM by Delnoij et al. (1997); right: distribution via a polynomial distribution function (see Darmana et al., 2005b).

since the bubbles will grow to sizes larger than the Eulerian grid.

\subsubsection{Bubble-emulsion interaction}

The interaction between the bubbles and the emulsion phase is a two-way coupling mechanism. The bubble phase affects the continuous phase via the void fraction and the source term in the Navier-Stokes equation. On the other hand, the velocity of the continuous phase influences the force balance of the bubbles via the slip velocity in the drag equation and via the virtual mass force. The source term $S$ in the Navier-Stokes equation is the momentum transfer rate from the bubbles to the emulsion phase per unit volume and is given by

$\bar{S}=-\frac{1}{V_{\text {cell }}} \sum_{\forall i \in \text { cell }}\left(\bar{F}_{d, i}+\bar{F}_{v m, i}\right)$.

In the conventional DBM developed for gas-liquid flows (Delnoij, 1999), the bubbles were much smaller than the Eulerian grid, which allowed mapping of the bubble quantities to the eight surrounding Eulerian cells via a volume-averaging technique, as is demonstrated in 2D in Fig. 3. In the DBM for gas-solid fluidised beds, the bubbles coalesce and grow to a size much larger than the grid size required to resolve the emulsion velocity patterns accurately. In this case the volume averaging technique cannot be applied. To map the momentum of bubbles that are larger than a grid cell, a normalised polynomial distribution function $(D)$ is used to distribute the momentum over the surrounding cells (in both the $x, y$ and $z$ direction) and the same function is used to translate Eulerian information (i.e. emulsion velocities) to the position of the bubble (Deen et al., 2004)

$$
\begin{aligned}
D\left(x_{i}-x_{i, b}\right)= & \frac{15}{16}\left[\frac{\left(x_{i}-x_{i, b}\right)^{4}}{n^{5}}-2 \frac{\left(x_{i}-x_{i, b}\right)^{2}}{n^{3}}+\frac{1}{n}\right] \\
& -n \leqslant\left(x_{i}-x_{i, b}\right) \leqslant+n,
\end{aligned}
$$

where $n=3 d_{b}$ was used in this work. The use of a distribution function to map the bubble quantities over the neighbouring Eulerian cells is justified, because the averaged larger scale effects of the bubbles on the emulsion phase velocity profiles 


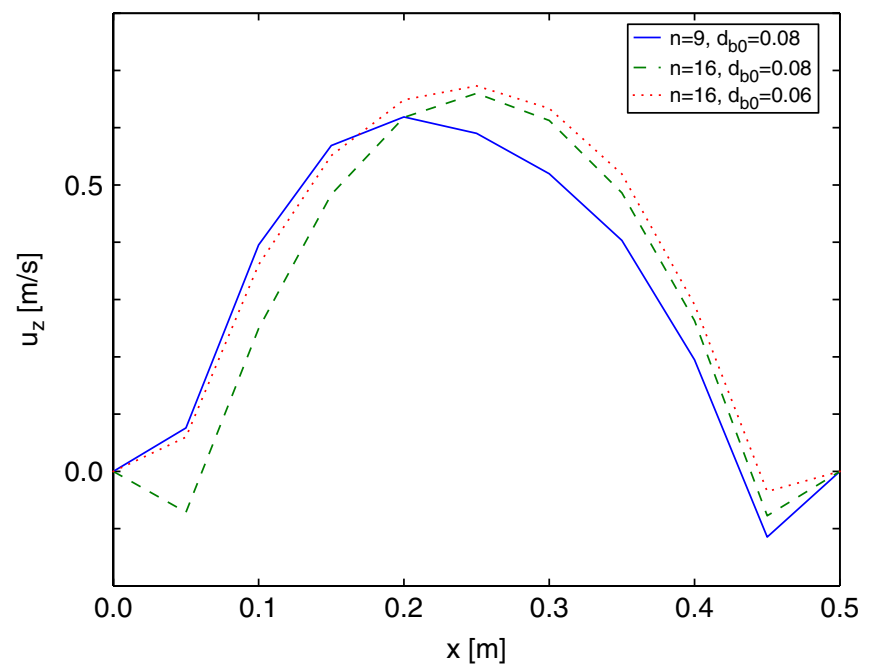

Fig. 4. Effect of the initial bubble size $\left(d_{b 0}\right)$ and the number of nozzles $(n)$ on the time-averaged lateral emulsion velocity profile while the superficial gas velocity was kept constant.

Table 3

Base case settings used in the DBM

\begin{tabular}{ll}
\hline Variable & Value \\
\hline Emulsion density & $400 \mathrm{~kg} / \mathrm{m}^{3}$ \\
Emulsion viscosity & $0.1 \mathrm{~Pa} \mathrm{~s}$ \\
Gas density & $25 \mathrm{~kg} / \mathrm{m}^{3}$ \\
Initial bubble diameter & $0.08 \mathrm{~m}$ \\
Superficial gas velocity & $0.25 \mathrm{~m} / \mathrm{s}$ \\
Number of nozzles & 49 \\
NX & 20 \\
NY & 20 \\
NZ & 60 \\
Width & $1.0 \mathrm{~m}$ \\
Depth & $1.0 \mathrm{~m}$ \\
Height & $3.0 \mathrm{~m}$ \\
Time step flowsolver & $5.0 \times 10^{-3} \mathrm{~s}$ \\
Time step bubbles & $5.0 \times 10^{-4} \mathrm{~s}$ \\
$C_{v m}$ & 0.5 \\
$C_{D}$ & 2.67
\end{tabular}

are of interest and not the detailed velocity profile in the vicinity of a single bubble.

\section{Model verification}

To investigate the effect of the number of nozzles and the initial bubble diameter, simulations have been carried out where only these parameters have been varied while keeping the superficial gas velocity constant (see Fig. 4). The simulation settings for the base case have been summarised in Table 3. In view of the required calculation times the dimensions of the bed were $0.5 \times 0.5 \times 1.5 \mathrm{~m}$ for these test simulations. It can be concluded that the simulations with these different inlet conditions produce very similar time-averaged (over $160 \mathrm{~s}$ ) lateral emulsion velocity profiles, indicating that the initial bubble size and number of bubbles do not affect the emulsion phase circulation patterns much.

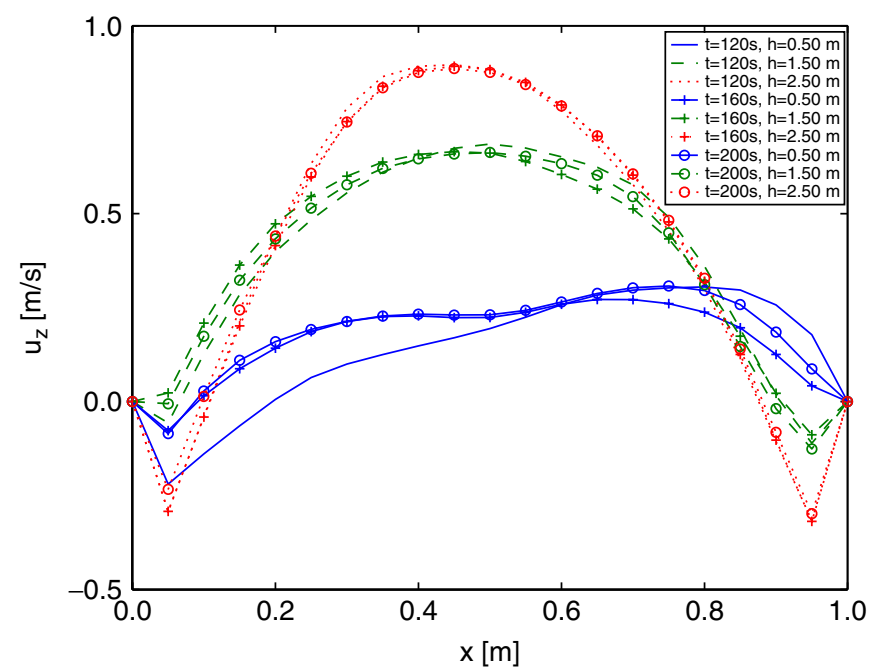

Fig. 5. Effect of averaging period on the time-averaged lateral emulsion velocity profile at different heights in the bed and a depth of $0.5 \mathrm{~m}$.

In order to check whether the time-averaging was carried out over a sufficiently long period, the time-averaged emulsion velocity for the base case is depicted in Fig. 5 averaging over 120, 160 and $200 \mathrm{~s}$ for different heights in the fluidised bed. From this figure it can be concluded that an averaging period of $160 \mathrm{~s}$ is adequate.

\section{DBM simulation results}

In the base case simulation, the rectangular fluidised bed has a width and depth of $1 \mathrm{~m}$ and a height of $3 \mathrm{~m}$. Although, a fluidised bed in industry is even larger than the dimensions used here in the simulations, it has been indicated in the literature that a fluidised bed diameter $D>0.50 \mathrm{~m}$ should already capture qualitatively the main characteristic flow patterns in the fluidised bed (Werther, 1974). The physical properties of the emulsion phase and the bubbles used in the simulations resemble the values that prevail in an industrial scale olefin polymerisation reactor at elevated pressure and are summarised in Table 3. The emulsion phase shear viscosity is roughly estimated to be $0.1 \mathrm{~Pa} \cdot \mathrm{s}$. Other values used in literature for the emulsion phase viscosity are in the same order of magnitude (Krishna and van Baten, 2001; Kobayashi et al., 2000). The initial bubble diameter is chosen to be $8 \mathrm{~cm}$ (estimated with Eq. (8)) and the bubbles are allowed to coalesce until a maximum bubble diameter of $20 \mathrm{~cm}$.

Firstly, the effect of bubble coalescence on the time-averaged emulsion phase velocity profile is studied. Thereafter, the lateral profiles of the visible bubble flow computed with the DBM is compared with an experiment carried out by Werther (1974). Subsequently, the effect of superficial gas velocity on the emulsion velocity patterns is studied and finally a DBM calculation for a real industrial scale fluidised bed is presented to demonstrate the capabilities of the model. An overview of the simulations is given in Table 4. 
Table 4

Overview of the different simulation cases

\begin{tabular}{lll}
\hline & Coalescence & $u_{0}(\mathrm{~m} / \mathrm{s})$ \\
\hline Base case & Yes & 0.25 \\
Case 1 & No & 0.25 \\
Case 2 & Yes & 0.32 \\
\hline
\end{tabular}

\subsection{Effect of coalescence}

In Figs. 6 and 7 different snapshots and the corresponding emulsion phase velocity fields of the base case simulation are shown. In Kunii and Levenspiel (1991) it is stated that the emulsion flow reflects the rise pattern of the bubbles. The upflow emulsion region should be rich in bubbles and the downflow regions should have few rising bubbles. In Fig. 6 this pattern can be clearly observed. Time-averaging of the instantaneous emulsion velocity profiles results in a symmetric velocity profile as is shown in Fig. 8(a). The simulation was time-averaged over $190 \mathrm{~s}$, starting after $10 \mathrm{~s}$ of simulation to avoid start-up effects. The upwards emulsion velocity in the centre of the bed is low in the bottom part of the bed and increases with height, which can be ascribed to bubble coalescence. Since, larger bubbles have higher rise velocities, the emulsion phase velocity will also be higher in the top of the bed due to the bubble-emulsion phase momentum transfer.

In Fig. 9 the time-averaged lateral profiles of the bubble velocity are shown as a function of the height in the fluidised bed and in Fig. 10 the corresponding averaged bubble diameter as a function of the height above the distributor is depicted. Both figures demonstrate that bubble coalescence occurs till the top of the bed and explains the emulsion velocity profile shown in Fig. 8(a).

To demonstrate the effect of coalescence on the dynamic behaviour of the fluidised bed, a DBM simulation has been carried out, with the same settings as in the base case simulation, where the bubbles were not allowed to coalesce. In Fig. 11 a snapshot of the fluidised bed without coalescence is depicted together with the corresponding instantaneous emulsion phase velocity field and in Fig. 8(b) the time-averaged emulsion velocity field is shown. When accounting for bubble coalescence, most of the bubbles rise through the central core of the bed. However, without bubble coalescence the bed is almost completely filled with bubbles. In Fig. 12 where the time averaged emulsion phase velocities are given at different heights in the fluidised bed. The main difference between the two cases is that when accounting for bubble coalescence, the emulsion phase
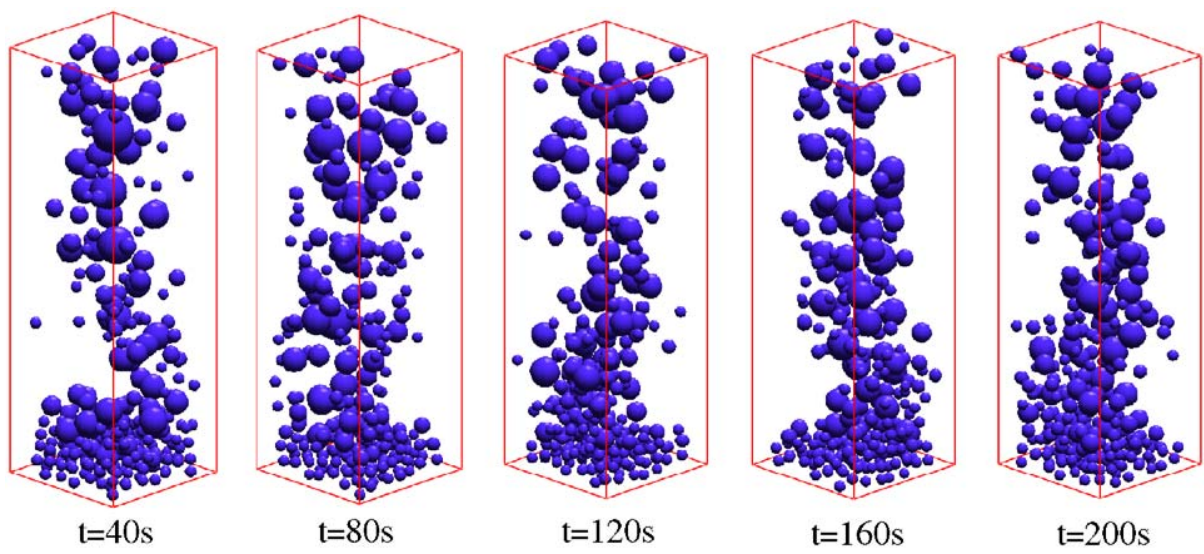

Fig. 6. Snapshots of the bubbles for the base case simulation at different moments in time.
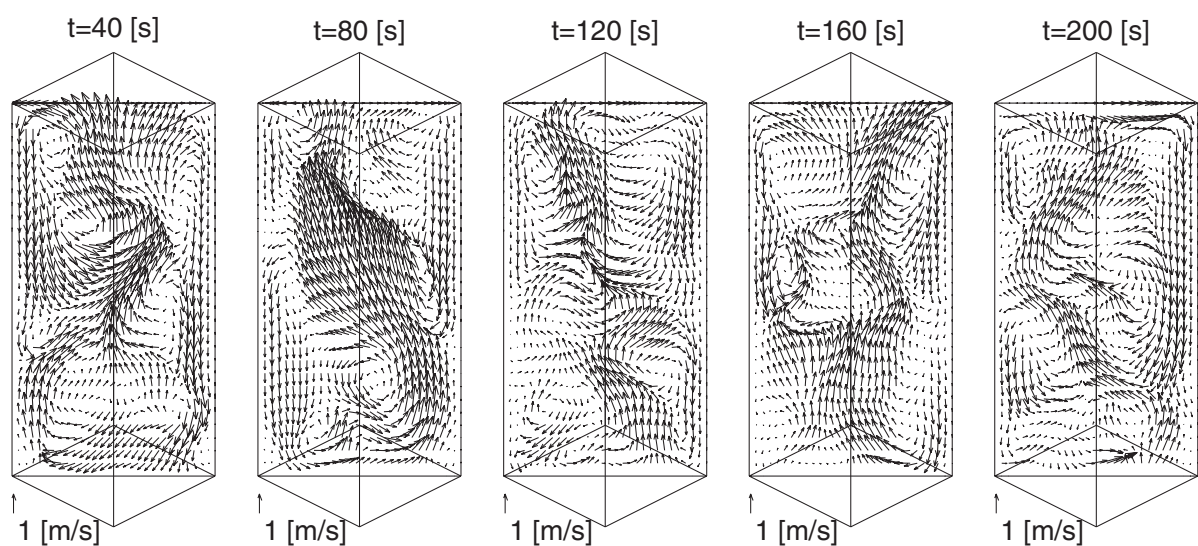

Fig. 7. Corresponding instantaneous vector plots for the base case simulation. 


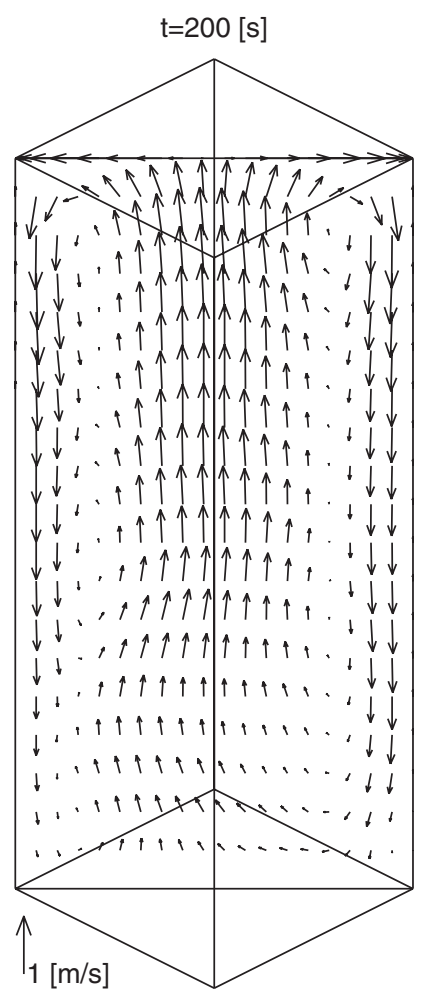

(a)

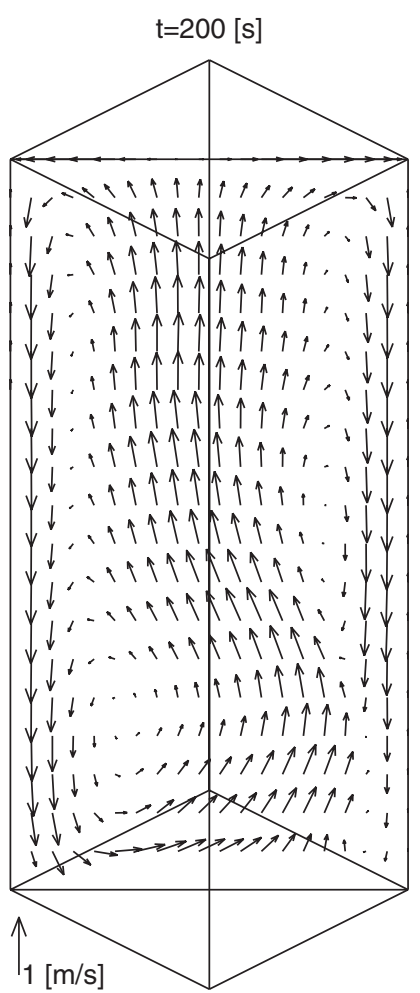

(b)

Fig. 8. Time-averaged velocity profile of the emulsion phase; (a) with coalescence; (b) without coalescence.

velocity keeps increasing till the top of the bed, contrary to the case without coalescence, where the rise velocity reaches a constant value. It can be concluded that bubble coalescence influences the magnitude of the emulsion velocity in the core of the bed and the extent of downflow along the walls, especially at higher bed heights, but has no direct influence on the shape of the macroscopic circulation patterns. In future work the additional effect of the wake acceleration force will be studied.

\subsection{Visible bubble flow rate}

The visible bubble flow rate is defined as the fraction of the total fluidising gas flow that is observable as bubbles. Werther (1974) measured the local bubble gas flow rate with a miniaturised capacitive probe in a cylindrical fluidised bed with a diameter of $20 \mathrm{~cm}$ and a height of $50 \mathrm{~cm}$. The bed was filled with quartz sand $\left(\rho=2640 \mathrm{~kg} / \mathrm{m}^{3}\right)$ and the minimum fluidisation velocity was $1.8 \mathrm{~cm} / \mathrm{s}$. The bed was fluidised with air with a superficial gas velocity of $9.0 \mathrm{~cm} / \mathrm{s}$. The results of these measurements are shown in Fig. 13, showing the lateral profile of the visible bubble flow rate at different heights in the bed. The zone where most of the bubbles are present is close to the wall for small heights above the distributor and moves towards the centre of the fluidised bed at higher heights above the distributor. The explanation given by Werther (1974) for the fact that the annular zone of increased bubble development moves towards the centre of the bed is the rapid increase of the bubble size due to coalescence. It was concluded that this bubble flow

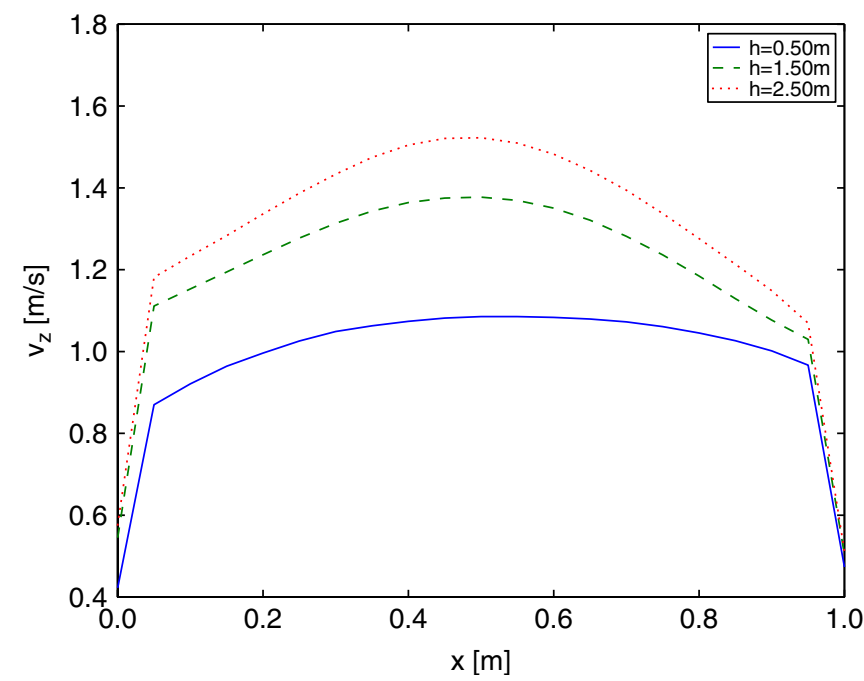

Fig. 9. Time-averaged lateral bubble velocity profile at different heights in the bed at a depth of $0.5 \mathrm{~m}$ for the base case.

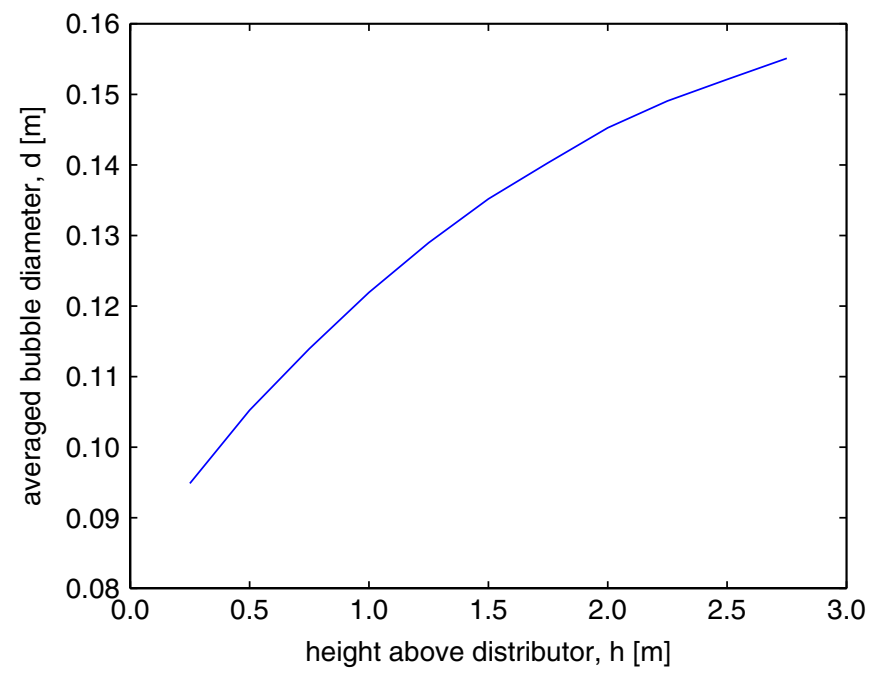

Fig. 10. Laterally and time-averaged bubble diameter as a function of the height above the distributor for the base case.

pattern is a characteristic property of gas/solid fluidised beds, independent of their diameter.

The same case has been simulated with the DBM, but for a squared fluidised bed instead of the cylindrical configuration used by Werther (1974). The emulsion phase density is set to $1300 \mathrm{~kg} / \mathrm{m}^{3}$ and the emulsion phase viscosity to $0.1 \mathrm{~Pa} \cdot \mathrm{s}$. The bubbles enter the bed via 100 nozzles with an initial bubble diameter of $8 \mathrm{~mm}$ and the bubbles can coalesce till a maximum diameter of $4 \mathrm{~cm}$. The computed lateral profile of the visible bubble flow rate with the DBM is depicted in Fig. 14. During a period of $90 \mathrm{~s}$ all the bubbles were counted that passed a cell with their centre of mass in the cross-sectional area of the bed at a certain height. Thereafter, the total volume of bubbles in that cell was divided by the cross-sectional area of that cell and by the averaging time. Here, the visible bubble flow pattern is plotted from the bed wall to the centre. All the data points 

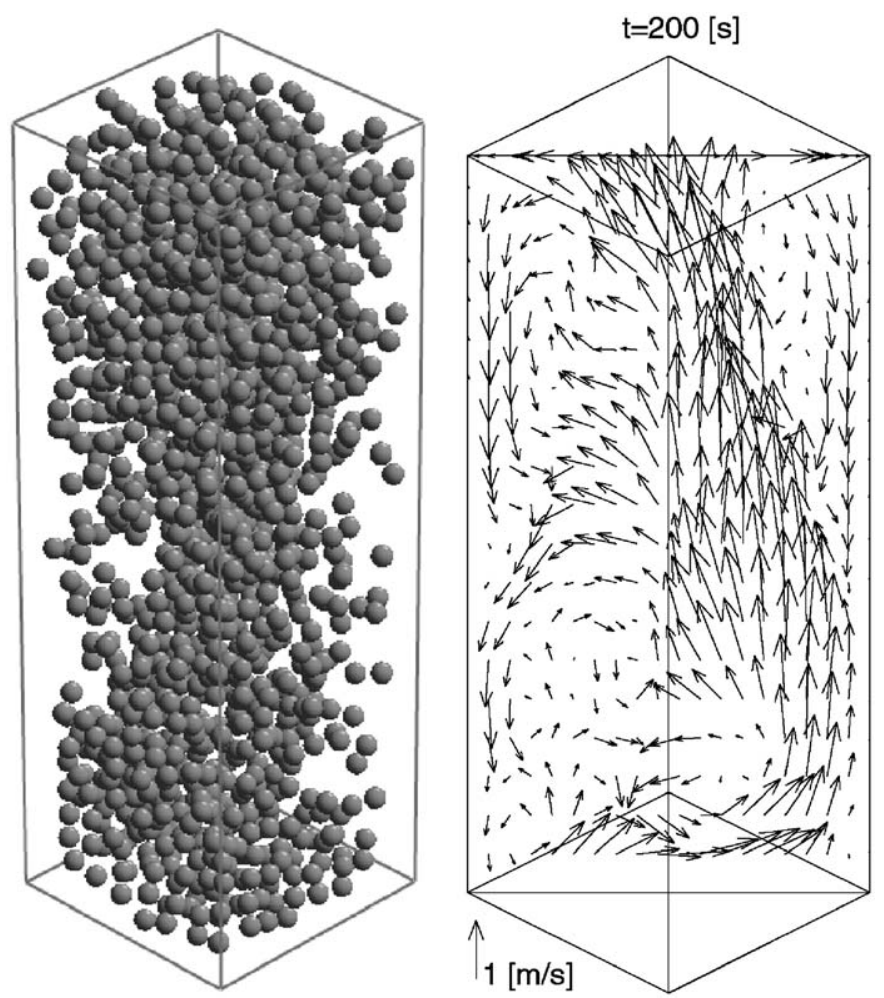

Fig. 11. Snapshot of the bubbles together with the corresponding instantaneous vector plot of the emulsion phase at $200 \mathrm{~s}$ for the base case settings without bubble coalescence (case 1)

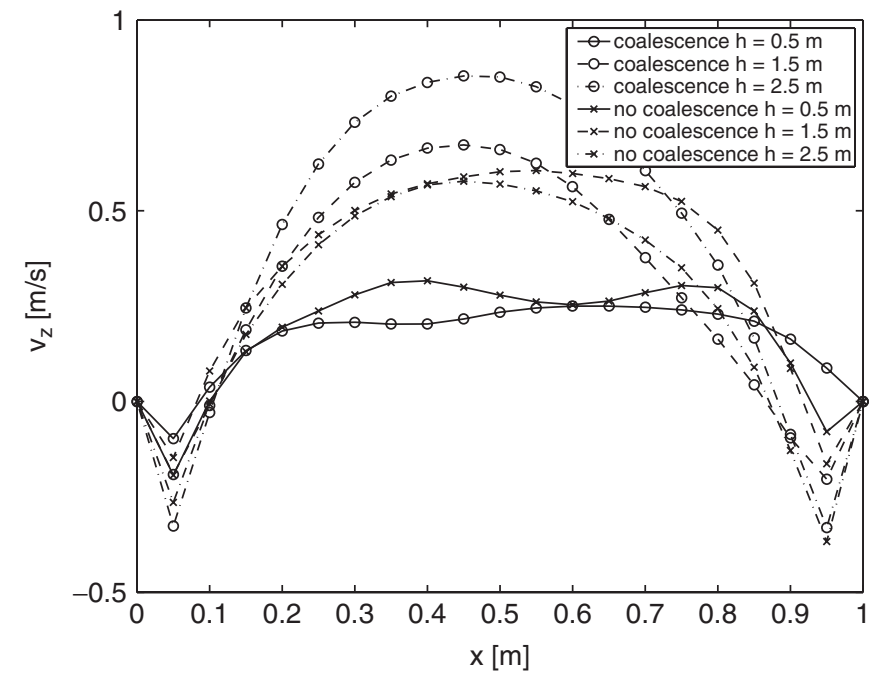

Fig. 12. Time-averaged velocity profile of the emulsion phase at different heights above the gas distributor at a depth of $0.5 \mathrm{~m}$ for the base case settings with and without coalescence (case 1).

in this figure represent the average of eight values around the centre of the bed as is indicated in Fig. 15. The visible bubble flow rate as a function of the bed height predicted by DBM resembles the experimental values by Werther (1974) rather well (within a range of $10 \%$ ). The maximum in the visible bubble flow rate profile indeed shifts towards the bed centre, although

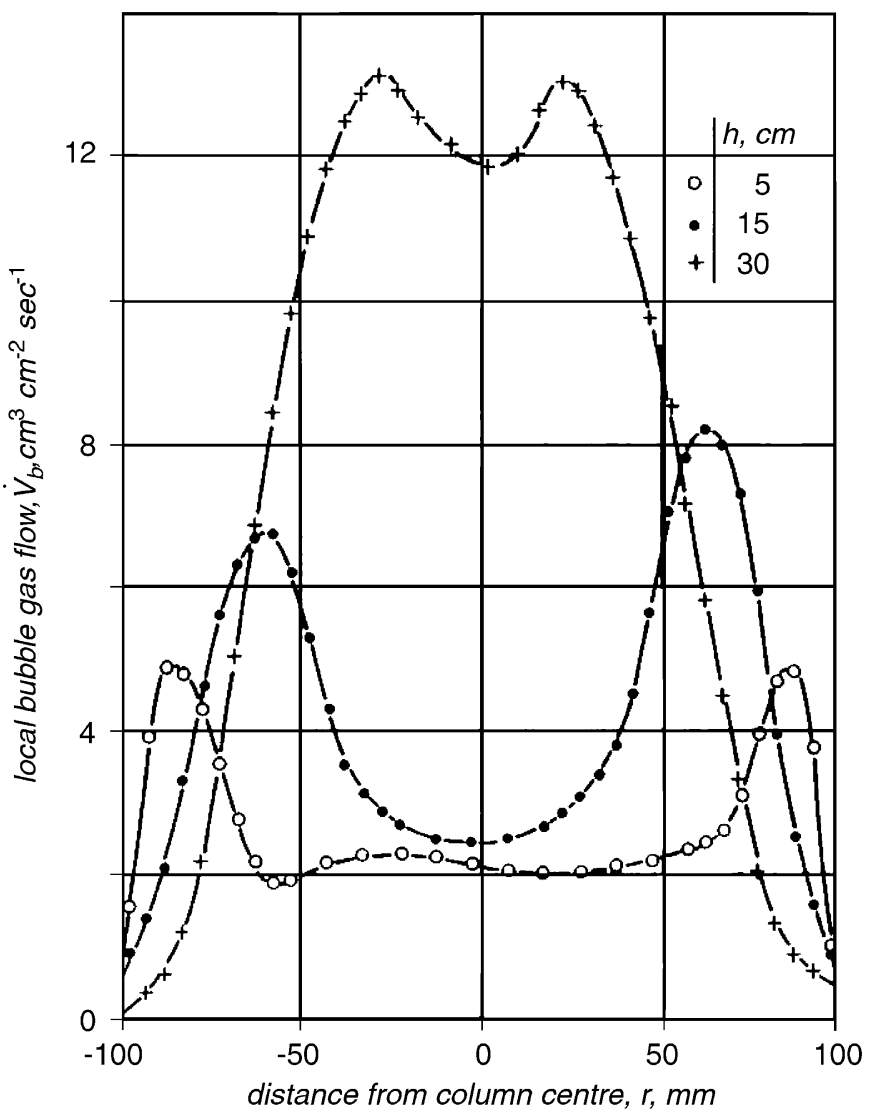

Fig. 13. The radial profile of the visible bubble flow rate in a fluidised bed of $200 \mathrm{~mm}$ diameter (from Werther, 1974).

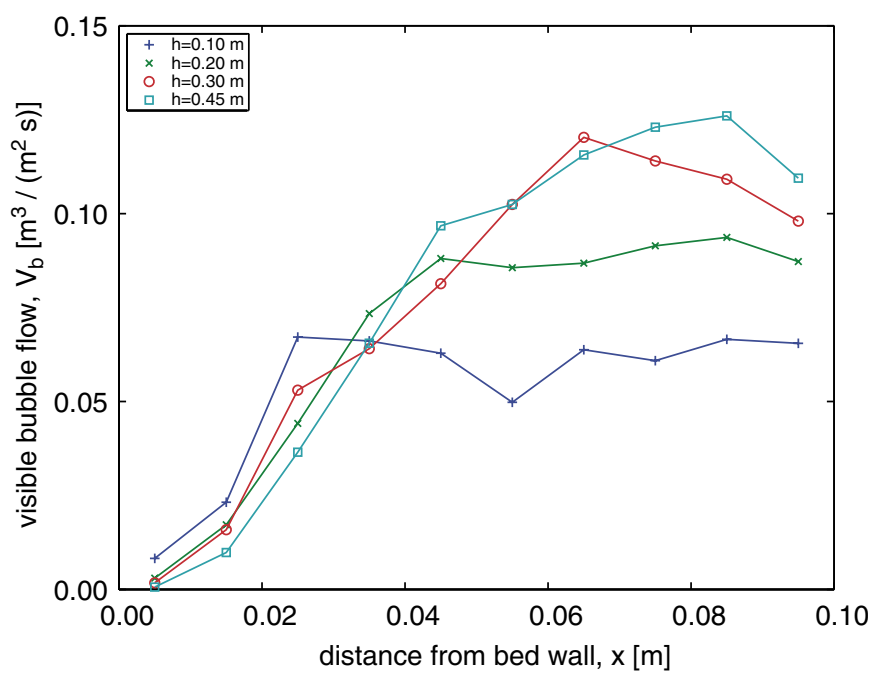

Fig. 14. Visible bubble flow rate at different heights and a depth of $0.1 \mathrm{~m}$.

the maxima computed by the DBM are less pronounced possibly related to the difference in shape of the bed (squared vs. cylindrical). From this figure, it can however be concluded that the DBM is able to predict the characteristic bubble flow patterns in a gas-solid fluidised bed. 


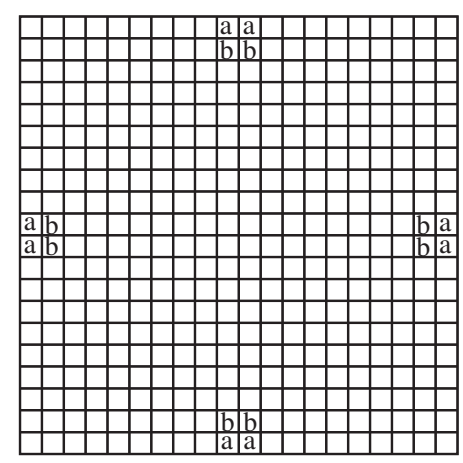

Fig. 15. Averaging method for constructing visible bubble flow rate picture. The cells marked with an ' $a$ ' are averaged to construct one data point, cells ' $b$ ' to make the second point and so forth.
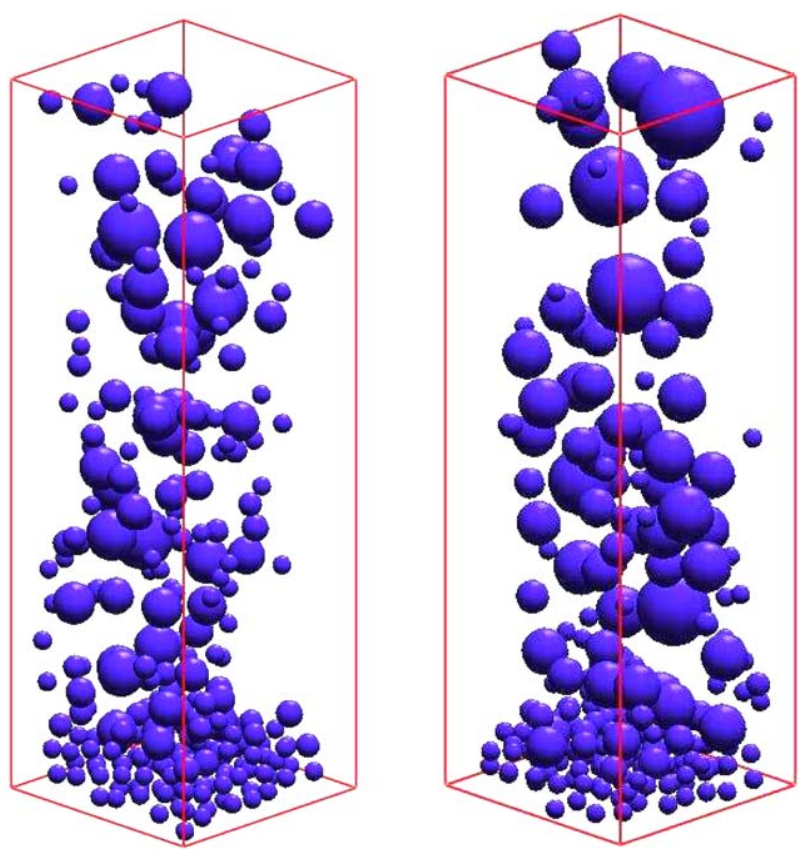

Fig. 16. Snapshots of the base case (left) and case 2 (right).

\subsection{Effect of superficial gas velocity}

To study the effect of the superficial gas velocity on the hydrodynamics of the fluidised bed a simulation has been carried out with increased superficial gas velocity $\left(u_{0}=0.32 \mathrm{~m} / \mathrm{s}\right.$, case 2). In Figs. 16 and 17 snapshots of the bubbles and the time-averaged emulsion phase velocity profiles of the base case and case 2 are depicted. From the snapshots it can be seen that a higher superficial gas velocity results in larger bubbles in the fluidised bed and also fewer bubbles are observed. Compared to the base case, a higher superficial gas velocity results in a somewhat higher upflow velocity of the emulsion phase, especially in the central part of the bed. In Fig. 18 the lateral profiles of the emulsion phase velocity are shown for the base case and case 2 at different heights in the bed.

At higher superficial gas velocities a larger percentage of the bubbles reaches the maximum diameter, and thus the number
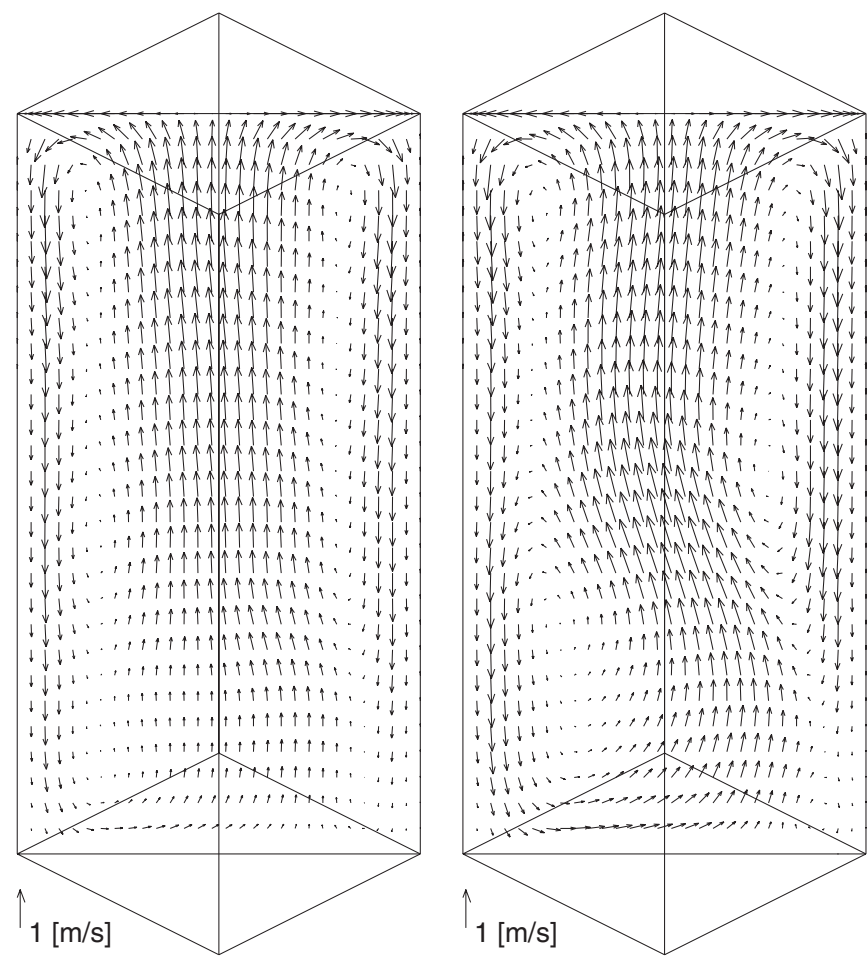

Fig. 17. Time-averaged vector plots of the base case (left) and case 2 (right).

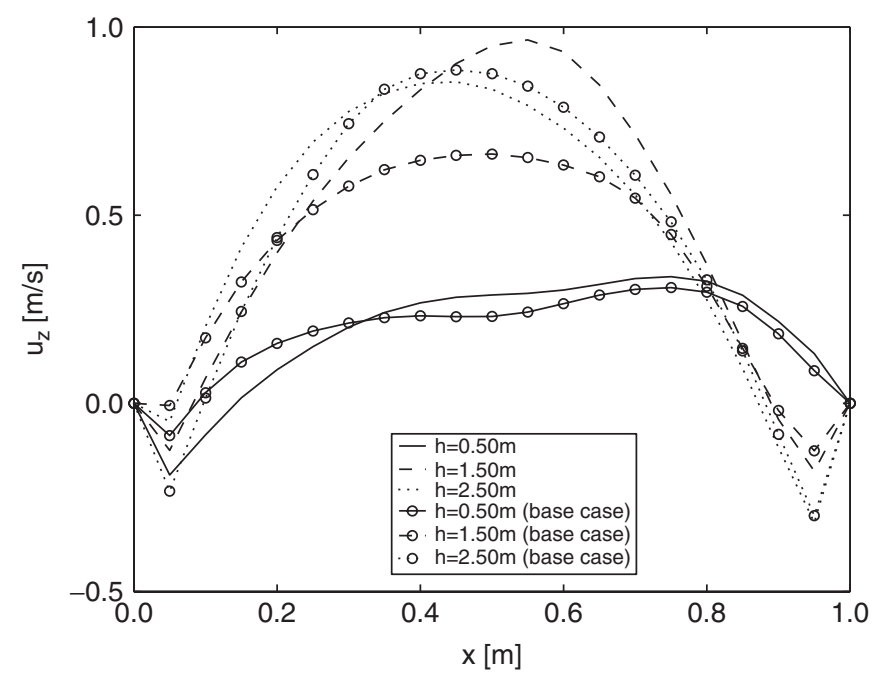

Fig. 18. Time-averaged lateral emulsion velocity profile at different heights in the bed at a depth of $0.5 \mathrm{~m}$ : effect of superficial gas velocity.

averaged bubble diameter increases, however, the maximum bubble rise velocity is fixed (because of the maximum bubble diameter). The emulsion phase velocity profile is mainly determined by momentum exchange with the larger bubbles. Hence, the emulsion phase velocity profile will no longer increase at higher bed heights when operating at higher superficial gas velocities, as is shown in Fig. 19.

The influence of the height above the distributor on the bubble diameter can be fitted using a generalised Darton's 


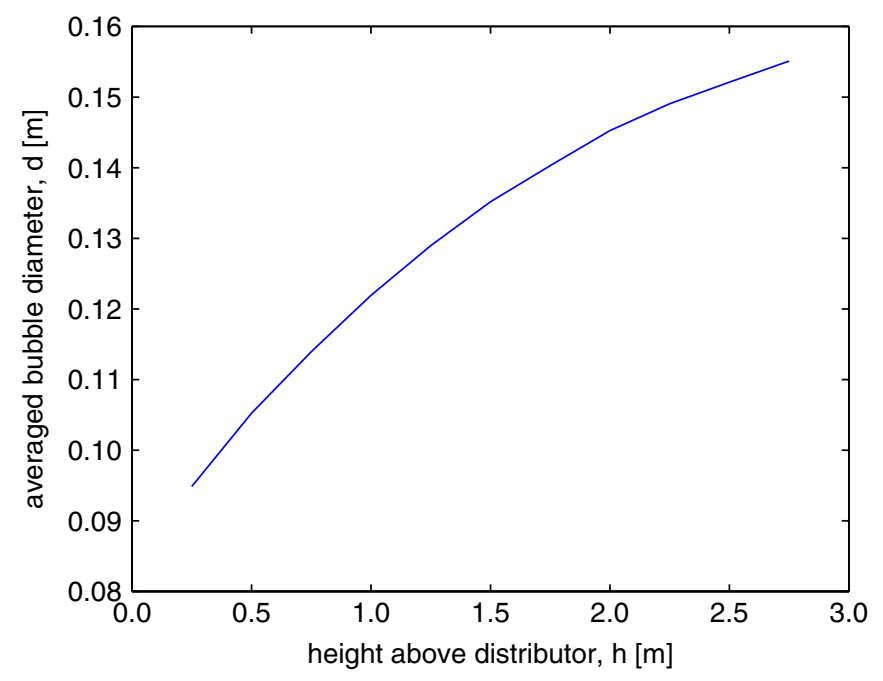

Fig. 19. Laterally and time-averaged bubble diameter as a function of the height above the distributor: effect of superficial gas velocity.

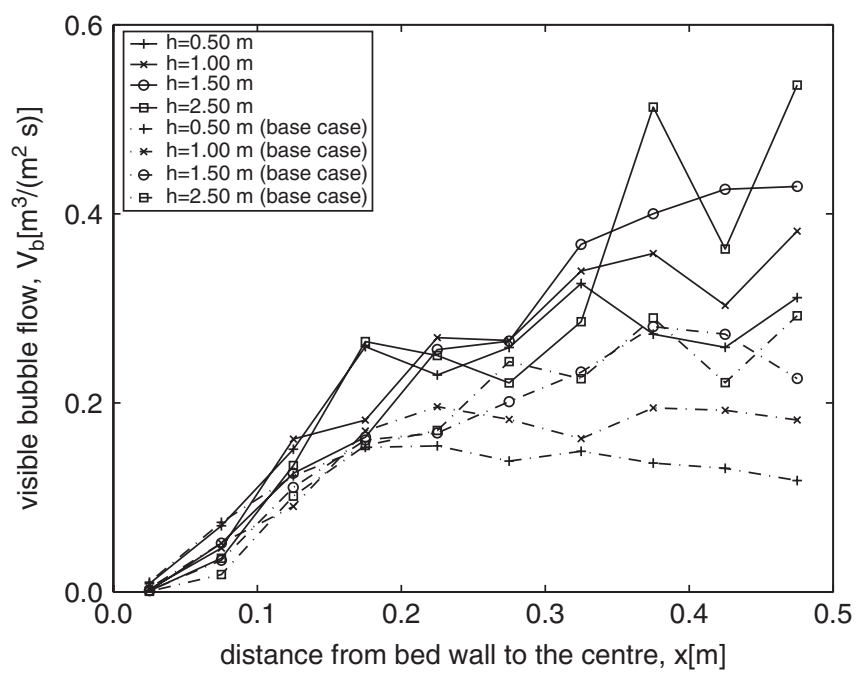

Fig. 20. Effect of superficial gas velocity on the lateral profiles of the visible bubble flow rate.

equation

$d_{b}=c\left(u-u_{m f}\right)^{A}\left(h+4 \sqrt{A_{0}}\right)^{B} g^{-0.2}$.

The value for exponent B fitted from Fig. 19 is approximately 0.2 , which is much lower than the exponent proposed by Darton et al. (1977), 0.8. This difference can be explained by the fact that in the DBM the bubbles grow until a pre-defined maximum bubble size, which is probably smaller than the maximum bubble size encountered in the experiments by Darton et al. (1977). In Fig. 20 the effect of the superficial gas velocity on the visible bubble flow profile is depicted. The visible bubble flow is higher for the case with a higher superficial gas velocity, since larger bubbles are formed that rise with a higher rise velocity.

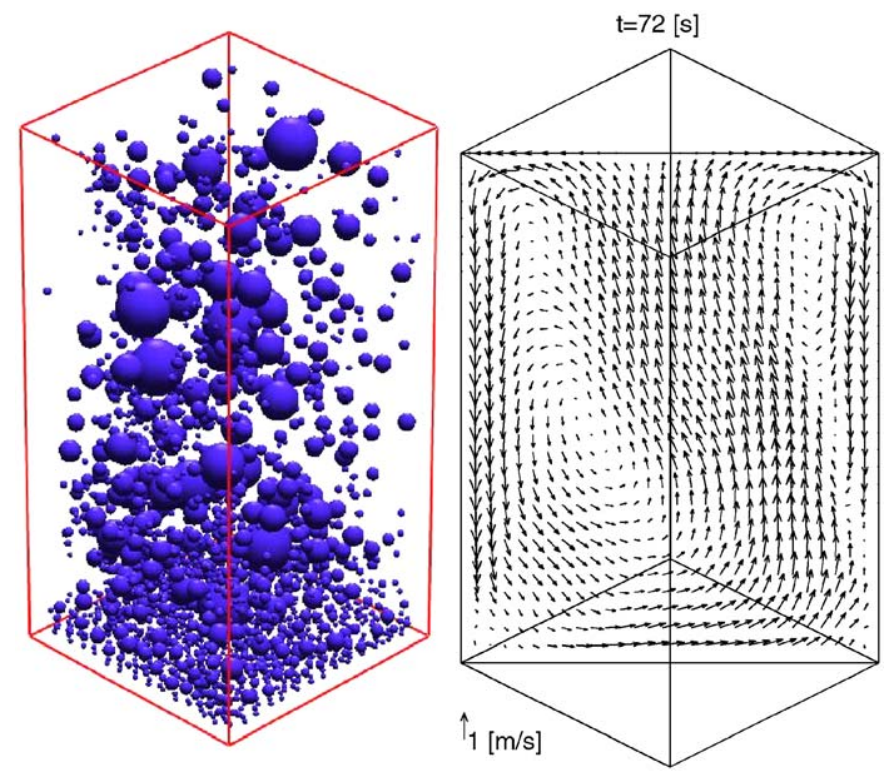

Fig. 21. Snapshot of the bubbles and the time-averaged emulsion phase velocity field for a DBM simulation for an industrial scale fluidised bed $(4 \mathrm{~m} \times 4 \mathrm{~m} \times 8 \mathrm{~m})$.

\subsection{Industrial scale fluidised bed}

In the previous paragraphs, the hydrodynamics have been studied of fluidised beds at an intermediate scale $(1 \mathrm{~m} \times 1 \mathrm{~m} \times$ $3 \mathrm{~m}$ ). However, an industrial scale fluidised bed reactor used for gas phase olefin polymerisations is even larger. In this paragraph it is demonstrated that the DBM is also capable of modelling the hydrodynamics of an industrial scale fluidised bed reactor. In Fig. 21 a snapshot of the bubbles and the time-averaged emulsion phase velocity field are depicted, for a fluidised bed with a dimension of $4 \mathrm{~m} \times 4 \mathrm{~m} \times 8 \mathrm{~m}(40 \times 40 \times 40$ computational cells). The bubbles entered the fluidised bed via 196 nozzles with an initial bubble diameter of $8 \mathrm{~cm}$ and the maximum bubble diameter was set to $80 \mathrm{~cm}$. The other simulation settings were kept the same as for the base case simulation.

Imagine to model a fluidised bed with this size with a two fluid model approach. To capture the bubble dynamics using a continuum model a minimum grid size of typically about $5 \mathrm{~mm}$ is required for sufficient accuracy. This will result in a simulation with $800 \times 800 \times 1600\left(\sim 10^{9}\right.$ ! $)$ computational cells to model a fluidised bed of industrial scale. With the computer power currently available this will be an impossible job and will remain impossible in the foreseeable future. However, with the DBM the large-scale circulation patterns prevailing in industrial scale fluidised bed reactors can be simulated, provided that an accurate and detailed description of the bubble dynamics and bubble coalescence and splitting is implemented.

\section{Conclusions}

A discrete bubble model (DBM), an Euler-Lagrange model, has been developed to model the large-scale circulation patterns prevailing in industrial scale fluidised bed reactors. The DBM, 
originally developed to describe gas-liquid bubble columns, has been modified to simulate gas-solid freely bubbling fluidised beds. The mapping of Lagrangian information to the Eulerian grid and vice versa has been adapted to cope with bubbles larger than an Eulerian grid cell. Moreover, a drag model for a single bubble rising in a fluidised bed was implemented according to the Davies-Taylor relation.

Comparison of a DBM simulation that accounted for bubble coalesce with a simulation without bubble coalescence showed the significant influence of coalescence on the large-scale circulation patterns in the emulsion phase, especially the magnitude of the emulsion phase velocity in the core of the bed and the extent of downflow along the walls. Since, the DBM tracks the bubbles explicitly, bubble coalescence can be accounted for in a direct way.

The DBM results were compared qualitatively with experimental results carried out by Werther (1974) for the characteristic visible bubble flow patterns in freely bubbling fluidised beds. In these experiments a zone of increased bubble development was observed that shifted towards the centre of the bed. The DBM results showed a similar characteristic visible bubble flow pattern, although the zone of preferred bubble flow was somewhat less pronounced.

A higher superficial gas velocity did not change the large emulsion circulation patterns much. A slightly higher timeaveraged emulsion velocity was found in the middle of the bed, as a result of the bubble coalescence.

Finally, it was demonstrated that the DBM is able to model the hydrodynamics of industrial scale fluidised bed reactors $(4 \mathrm{~m} \times 4 \mathrm{~m} \times 8 \mathrm{~m})$ within acceptable calculation times.

Generally, it can be stated that the DBM is able to capture the characteristic hydrodynamic behaviour of freely bubbling fluidised beds. Future work will be focused on improving the closures for the bubble behaviour (e.g. wake effects on bubble rise velocity) and studying the effects of different aspect ratios on the large-scale circulation patterns in a fluidised bed.

\section{Notation}

AF acceleration factor, dimensionless

$C_{D} \quad$ drag coefficient, dimensionless

$C_{n} \quad$ explicit term in the $z$-momentum equation, $\mathrm{kg} /\left(\mathrm{m}^{2} \mathrm{~s}\right)$

$C_{v m} \quad$ virtual mass coefficient, dimensionless

$d \quad$ diameter, $\mathrm{m}$

$d_{b 0} \quad$ initial bubble diameter, $m$

$D$ distribution function to map the momentum of bubbles, $1 / m$

$D_{T} \quad$ fluidised bed diameter, $\mathrm{m}$

$F \quad$ force, $\mathrm{N}$

$F_{d} \quad$ drag force, $\mathrm{N}$

$F_{g} \quad$ gravity force, $\mathrm{N}$

$F_{p} \quad$ pressure force, $\mathrm{N}$

$F_{v m} \quad$ virtual mass force, $\mathrm{N}$

$g \quad$ gravitational acceleration, $\mathrm{m} / \mathrm{s}^{2}$

$m \quad$ mass, $\mathrm{kg}$

$P \quad$ pressure, $\mathrm{Pa}$
$P_{t} \quad$ orifice pitch, $\mathrm{m}$

$R \quad$ radius, $\mathrm{m}$

$R e \quad$ Reynolds number, dimensionless

$S \quad$ drag source term, $\mathrm{Pa}$

SF size factor, dimensionless

$t \quad$ time, $\mathrm{s}$

$u \quad$ continuum velocity, $\mathrm{m} / \mathrm{s}$

$v \quad$ velocity, $\mathrm{m} / \mathrm{s}$

$v_{b}^{0} \quad$ terminal rise velocity of bubble, $\mathrm{m} / \mathrm{s}$

$V \quad$ volume, $\mathrm{m}^{3}$

$V_{b} \quad$ visible bubble flow, $\mathrm{m}^{3} /\left(\mathrm{m}^{2} \mathrm{~s}\right)$

$x_{i} \quad$ spatial co-ordinate direction, $\mathrm{m}$

Greek letters

$\alpha \quad$ power-law function

$\varepsilon \quad$ volume fraction, dimensionless

$\rho$ density, $\mathrm{kg} / \mathrm{m}^{3}$

$\tau \quad$ stress tensor, $\mathrm{Pa}$

$\psi \quad$ scale factor

Subscripts

b bubble

cell computational cell

e emulsion

mf minimum fluidisation

\section{Acknowledgements}

The authors thank D. Darmana M.Sc. for his efforts in coding the DBM used in this work. This research forms part of the research programme of the Dutch Polymer Institute (DPI), Project \#231.

\section{References}

Auton, T.R., 1983. The dynamics of bubbles, drops and particles in motion in liquids. Ph.D. Thesis, University of Cambridge.

Centrella, J., Wilson, J.R., 1984. Planar numerical cosmology. II. The difference equations and numerical tests. Astrophysical Journal Supplement Series 54, 229-249.

Chiba, T., Kobayashi, H., 1972. Behavior of bubbles in gas-solid fluidized beds, initial formation of bubbles. Chemical Engineering Science 27, 965-972.

Choi, K.Y., Ray, W.H., 1985. The dynamic behaviour of fluidized bed reactors for solid catalysed gas phase olefin polymerization. Chemical Engineering Science 40, 2261-2279.

Collins, R., 1967. The effect of a containing cylindrical boundary on the velocity of a large gas bubble in a liquid. Journal of Fluid Mechanics 28, 97-112.

Darmana, D., Deen, N.G., Kuipers, J.A.M., 2005a. Detailed modeling of the hydrodynamics mass transfer and chemical reactions in a bubble column using a discrete bubble model. Chemical Engineering Science 60, 3383-3404.

Darmana, D., Deen, N.G., Kuipers, J.A.M., 2005b. Parallelization of an Euler-Lagrange model using mixed domain decomposition and a mirror domain technique: application to disperse gas liquid two phase flow. In: Computational Fluid Dynamics in Chemical Reaction Engineering IV, Barga, Italy, June, pp. 19-24.

Darton, R.C., Harrison, D., 1974. The rise of single gas bubbles in liquid fluidized beds. Transaction of Institution Chemical Engineers 52, 301-306. 
Darton, R.C., LaNauze, R.D., Davidson, J.F., Harrison, D., 1977. Bubble growth due to coalescence in fluidized beds. Transactions of the Institutions of Chemical Engineers 55, 274-280.

Davies, R.M., Taylor, G.I., 1950. The mechanics of large bubbles rising through extended liquids and through liquids in tubes. Proceedings Royal Society London A 200, 375-390.

Deen, N.G., van Sint Annaland, M., Kuipers, J.A.M., 2004. Multi-scale modeling of dispersed gas-liquid two-phase flow. Chemical Engineering Science 59, 1853-1861.

Delnoij, E., 1999. Fluid dynamics of gas-liquid bubble columns. Ph.D. Thesis, University of Twente.

Delnoij, E., Lammers, F.A., Kuipers, J.A.M., van Swaaij, W.P.M., 1997. Dynamic simulation of dispersed gas-liquid two-phase flow using a discrete bubble model. Chemical Engineering Science 52, 1429-1458.

Delnoij, E., Kuipers, J.A.M., van Swaaij, W.P.M., 1999. A three dimensional cfd model for gas-liquid bubble columns. Chemical Engineering Science 54, 2217-2226.

Geldart, D., 1973. Types of gas fluidization. Powder Technology 7, 285-292.

Goldschmidt, M.J.V., 2001. Hydrodynamic modelling of fluidised bed spray granulation. Ph.D. Thesis, University of Twente, Enschede, The Netherlands.

Hoomans, B.P.B., 1999. Granular dynamics of gas-solid two-phase flows. Ph.D. Thesis, University of Twente, Enschede, The Netherlands.

Kobayashi, N., Yamazaki, R., Mori, S., 2000. A study on the behavior of bubbles and solids in bubbling fluidized beds. Powder Technology 113, 327-344.

Krishna, R., van Baten, J.M., 2001. Using CFD for scaling up gas-solid bubbling fluidised bed reactors with Geldart A powders. Chemical Engineering Journal 82, 247-257.

Kuipers, J.A.M., van Duin, K.J., van Beckum, F.P.H., van Swaaij, W.P.M., 1993. Computer simulation of the hydrodynamics of two-dimensional gas-fluidized bed. Computers and Chemical Engineering 17, 839-858.
Kunii, D., Levenspiel, O., 1991. Fluidization Engineering, second ed. Butterworth-Heinemann, London.

Lapin, A., Lübbert, A., 1994. Numerical simulation of the dynamics of twophase gas-liquid flows in bubble columns. Chemical Engineering Science 49, 3661-3674.

Odar, F., Hamilton, W.S., 1964. Forces on a sphere accelerating in a viscous liquid. Journal of Fluid Mechanics 18, 302-314.

Pannala, S., Daw, C.S., Halow, J.S., 2003. Simulations of reacting fluidized beds using an agent-based bubble model. International Journal of Chemical Reactor Engineering 1 (A20), 1-18.

Pannala, S., Daw, C.S., Halow, J.S., 2004. Dynamic interacting bubble simulation (DIBS): an agent-based bubble model for reacting fluidized beds. Chaos 14 (2), 487-498.

Patankar, S.V., 1980. Numerical Heat Transfer and Fluid Flow. Taylor \& Francis, London.

Sokolichin, A., Eigenberger, G., Lapin, A., Lübbert, A., 1997. Dynamic numerical simulation of gas-liquid two-phase flows Euler/Euler versus Euler/Lagrange. Chemical Engineering Science 52, 611-626.

van den Hengel, E.I.V., 2004. Multi-level modelling of gas-liquid two-phase flow in a bubble column. Ph.D. Thesis, University of Twente, Enschede, The Netherlands.

van den Langenberg-Schenk, G., 1982. The rheology of gas fluidized powders as determined in a vertical standpipe. Ph.D. Thesis, Eindhoven University of Technology, The Netherlands.

Werther, J., 1974. Influence of the bed diameter on the hydrodynamics of gas fluidized beds. A.I.Ch.E. Symposium Series 70 (141), 53-62.

Werther, J., 1992. Fluidized-bed reactors. In: Elvers, B., Hawkins, S., Schulz, G. (Eds.), Principles of Chemical Reaction Engineering and Plant Design, vol. B4 of Ullmann's Encyclopedia of Industrial Chemistry, fifth ed. VCH Verlagsgesellschaft $\mathrm{mbH}$, Weinheim. 